\title{
Effect of Oestrogen Therapy on Plasma and Urinary Levels of Uric Acid
}

\author{
ANNE NICHOLLS, M. L. SNAITH, J. T. SCOTT
}

British Medical fournal, 1973, 1, 449-451

\section{Summary}

Uric acid clearance studies were carried out on a lowpurine diet in 22 trans-sexual men before and during oestrogen therapy for this condition (stilboestrol in 21 cases, ethinyloestradiol in one). Plasma uric acid fell in 15 of the subjects and urinary uric acid rose in 17 of 20 subjects in whom satisfactory collections were obtained. These changes are significant and it is suggested that hormonal influences are responsible for the known age and sex differences in plasma uric acid.

\section{Introduction}

Plasma levels of uric acid in adult women before the menopause are about $1 \mathrm{mg} / 100 \mathrm{ml}$ lower than those of men. The reason for this difference is not known, but it is possible that hormonal influences are important. The present study examines the effect of long-term administration of oestrogen on plasma and urinary uric acid.

\section{Subjects and Methods}

The study was carried out on 22 adult trans-sexual men aged 19-55 years who were under the care of Dr. John Randell and who were to undergo psychotherapy and oestrogen treatment. Both the purpose and the details of the study were carefully explained to the subjects and their collaboration was obtained

The patients were initially asked to take an alcohol-free, lowpurine diet (containing less than $200 \mathrm{mg}$ purine daily) for one week. They were instructed not to take any drugs which might affect uric acid metabolism. During the last three days, blood and 24-hour urine collections were obtained for basal uric acid and creatinine estimations. The subjects were then started on their treatment: 21 patients received stilboestrol in doses of $5-40 \mathrm{mg} /$ day (mean $20 \cdot 25 \mathrm{mg}$ ) while the remaining subject took ethinyloestradiol $0.4 \mathrm{mg}$ daily.

At the end of a period of from two weeks to 10 months (mean 10 weeks) the subjects, while remaining on hormone therapy, once again took a low-purine diet for one week, and further specimens were collected on the last three days for uric acid and creatinine clearances. There were no ill-effects resulting from this treatment, but most noticed some breast enlargement. Uric acid levels were estimated using an enzymic spectrophotometric method (Liddle et al., 1959).

\section{Results}

Plasma uric acid fell in 15 of the 22 subjects, the mean value before treatment being $4.8 \mathrm{mg} / 100 \mathrm{ml}( \pm$ S.D. 1.0) and that

\footnotetext{
Charing Cross Hospital, London W.C.2, West London Hospital, London W.6, and Kennedy Institute of Rheumatology, London
W.6.

ANNE NICHOLLS, M.R.C.P., Senior Medical Registrar (Present address: Westminster Hospital, London S.W.1)

M. L. SNAITH, M.R.C.P., Smith \& Nephew Research Fellow (Present address: Westminster Hospital, London S.W.1)

J. T. SCOTT, M.D., F.R.C.P., Consultant Physician
}

during treatment $4.1 \mathrm{mg} / 100 \mathrm{ml}( \pm$ S.D. $0 \cdot 9)$. This fall is significant ( $t$ test for paired differences, $\mathrm{P}<0.01$; fig. 1 ).

Urinary uric acid rose in 17 of 20 subjects in whom satisfactory collections were obtained, the mean value before treatment of $414 \mathrm{mg} / 24 \mathrm{hr}$ ( \pm S.D. 104) rising to $529 \mathrm{mg} / 24 \mathrm{hr}$ ( \pm S.D. 100). Uric acid clearance rose in 17 of the 20 subjects, from a mean value of $6.3 \mathrm{ml} / \mathrm{min}( \pm$ S.D. $1 \cdot 8$ ) to $9.1 \mathrm{ml} / \mathrm{min}$ ( \pm S.D. $2 \cdot 8$ ). These again are highly significant changes $(P<0.001$, figs. 2 and 3).

There was no correlation between fall in plasma uric acid or rise in urinary uric acid and the dosage of oestrogen; most of the subjects were taking $20 \mathrm{mg}$ of stilboesterol daily, and only two were taking very low or very high doses.

Owing to a technical error with loss of samples, results of plasma and urinary creatinine estimations were available in only

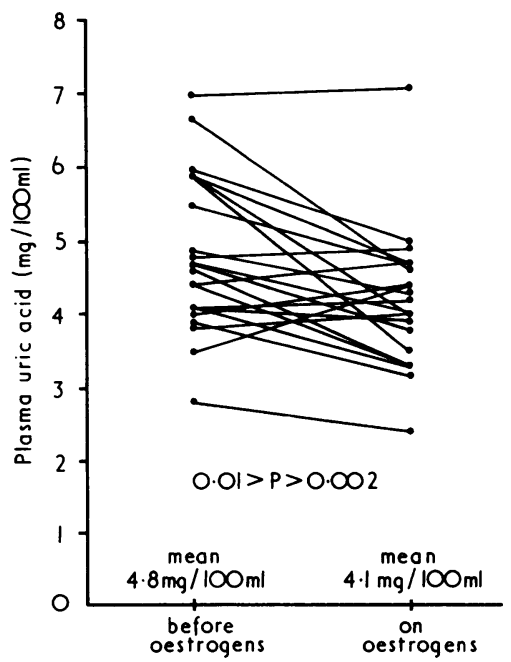

FIG. 1-Levels of plasma uric acid before and during oestrogen therapy.

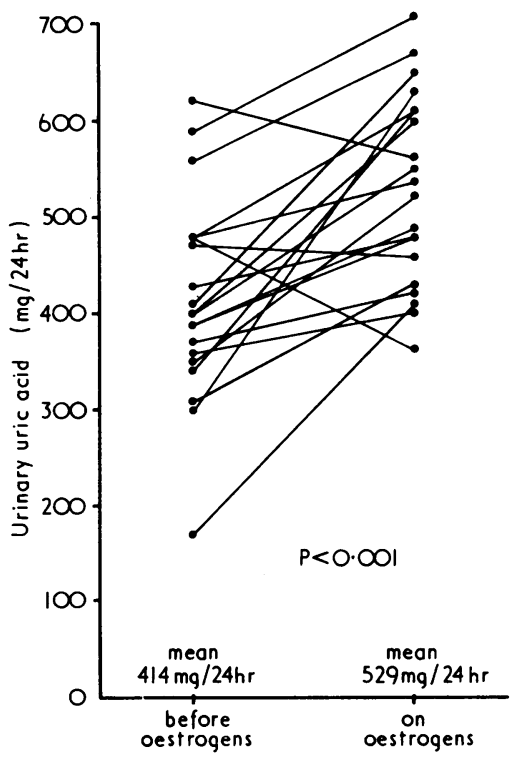

FIG. 2-Levels of urinary uric acid before and during oestrogen therapy. 


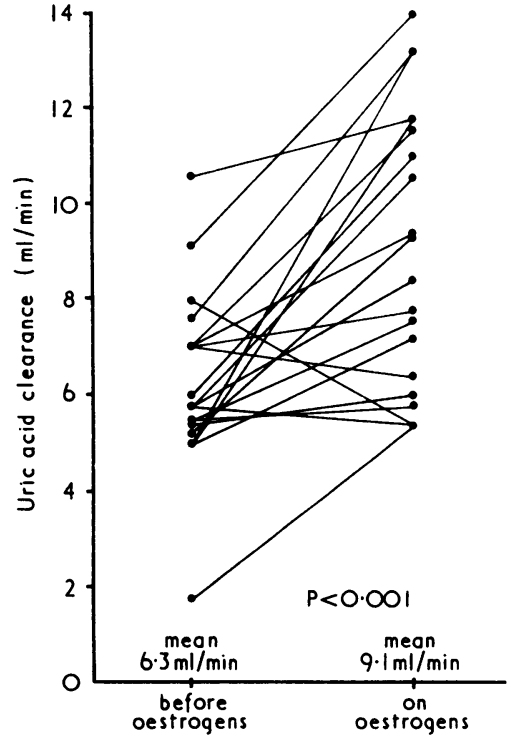

FIG. 3-Uric acid clearance before and during oestrogen therapy.

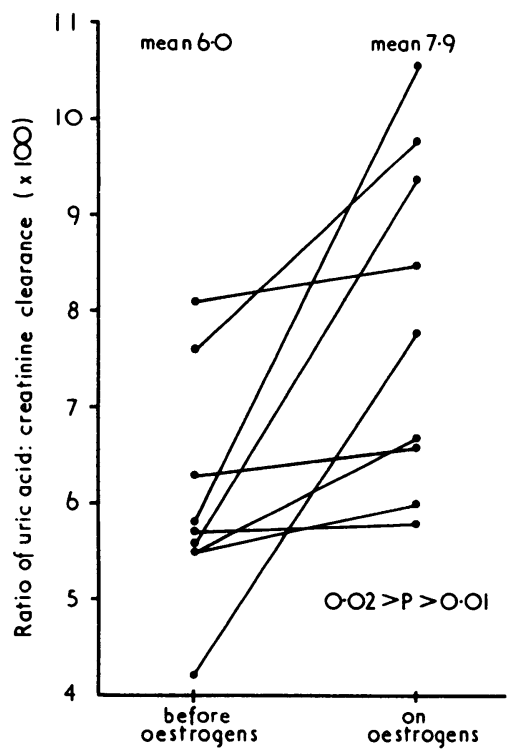

FIG. 4-Uric acid:creatinine clearance ratio $(x 100)$ before and during oestrogen therapy.

nine of the subjects before and during treatment. No significant change in plasma or urinary creatinine was found in these subjects, nor in creatinine clearance which was $103 \mathrm{ml} / \mathrm{min}$ ( \pm S.D. 23) before treatment and $116 \mathrm{ml} / \mathrm{min}$ ( \pm S.D. 20) on oestrogens. The ratio uric acid:creatinine clearance $(\times 100)$ rose in all of the subjects, from a mean value of $6.0( \pm$ S.D. $1.1)$ to $7.9( \pm$ S.D. 1.8$)$, a significant change $(P<0.02$, fig. 4).

The one subject receiving ethinyloestradiol showed a fall in plasma uric acid from 5.9 to $3.5 \mathrm{mg} / 100 \mathrm{ml}$ and a rise in urinary uric acid from 475 to $542 \mathrm{mg}$ daily, changes similar to those seen in most patients receiving stilboesterol.

\section{Discussion}

The plasma level of uric acid, low in children, rises in boys at the time of puberty, so that the average value in men is about $1.0 \mathrm{mg} / 100 \mathrm{ml}$ higher than that in women (Mikkelsen et al., 1965). A rise takes place in women at the time of the menopause, the mean level approaching, but not quite equalling, that of men. The rarity of gout in young women is no doubt at least partly due to this biochemical difference between the sexes.
The underlying causes of these age and sex differences are not clear, but there appear to be differences in the renal clearance of uric acid. Wolfson et al. (1949) found that uric acid clearance was rather higher in healthy women than in men, averaging $12.67 \mathrm{ml} / \mathrm{min}$ in women and $10.38 \mathrm{ml} / \mathrm{min}$ in men. Scott and Pollard (1970), studying the healthy relatives of gouty patients, made similar observations. Mean uric acid clearance in male relatives was $7.7 \mathrm{ml} / \mathrm{min}$ and in female relatives $8.9 \mathrm{ml} / \mathrm{min}$, and the ratio of uric acid to creatinine clearance was greater in women than in men.

It is therefore possible that androgenic or oestrogenic hormones can influence uric acid excretion. Wolfson et al. (1949) suggested that the age and sex differences in uric acid excretion were due to differences in androgen production. Graber-Duvernay and Graber-Duvernay (1957) described the cases of three women who developed acute attacks of gout shortly after receiving androgen therapy for a variety of conditions, although detailed estimations of plasma uric acid before and after treatment were not performed on these patients.

In the present study the administration of oestrogens, usually stilboestrol, caused a highly significant increase in uric acid clearance due presumably to an alteration in renal tubular activity, either impaired reabsorption or increased secretion (Gutman and Yü, 1961). Administration of stilboestrol has been shown to produce various effects on kidney structure and function. Implantation of stilboestrol in guinea-pigs causes cellular proliferation in glomeruli with deposition of laminated extracellular material (Trevan, 1956) and later tubular dilation and atrophy with interstital fibrosis (Chesterman et al., 1956). Prolonged administration in high doses to male golden hamsters produces epithelial tumours of the cortical tubule (Horning and Whittick, 1954). Oestrogen administered to dogs (Thorn and Engel, 1938) and to human patients (Preedy and Aitken, 1956) diminishes excretion of water, sodium, and chloride for a few days, the pattern of excretion then reverting to normal. Potassium excretion is increased in guinea-pigs (Chesterman et al., 1956). Some of these changes resemble those seen in hyperaldosteronism and a subcutaneous injection of oestradiol in rats has been shown to increase faecal excretion of an aldosterone-like substance (Llaurado et al., 1962). Glomerular filtration rate and renal plasma flow in humans are not altered by oestradiol (Dean et al., 1945; Dignam et al., 1956), but a transient increase of creatinine and diodone clearances has been described in bitches given stilboestrol (Dance et al., 1959). No studies relating to uric acid excretion have previously been carried out.

Many factors are known to influence the excretion of uric acid, and hyperuricaemia has been described in relation to endocrine disorders-namely, hyperparathyroidism (Mintz et al., 1961; Scott et al., 1964) and myxoedema (Leeper et al., 1960). The effects of natural oestrogens are not known; they may not share the property of a synthetic oestrogen which has such a different molecular structure. The uricosuric action of stilboestrol found in this study nevertheless suggests the possibility that natural androgens and oestrogens have suppressing and enhancing effects respectively on uric acid excretion and that these are responsible for the age and sex differences in plasma uric acid.

We should like to acknowledge the helpful collaboration of Dr. John Randell, consultant psychiatrist, Charing Cross Hospital, and patients under his care, without which this study would not have been possible. Biochemical investigations were carried out by Mrs. Hannelore Yablonsky. We are also grateful to Dr. W. Y. Loebl for discussion and to the Arthritis and Rheumatism Council and Burroughs Wellcome Ltd. for financial support.

Requests for reprints should be addressed to Dr. J. T. Scott, Mathilda and Terence Kennedy Institute of Rheumatology, Bute Gardens, Hammersmith, London W6 7DW.

\section{References}

Chesterman, F. C., Franks, L. M., Knudsen, E. T., and Williams, P. C.

Dance, P., Lloyd, S., and Pickford, M. (1959). Fournal of Physiology, 145, 225. 
Dean, A. L., Abels, J. S., and Taylor, H. C. (1945). fournal of Urology, 53, 647.

Dignam, W. S., Voskian, J., and Assali, N. S. (1956). Fournal of Clinical Endocrinology and Metabolism, 16, 1032.

Graber-Duvernay, J., and Graber-Duvernay, B. (1957). Rhumatologie, 9, 261.

Gutman, A. B., and Yü, T. F. (1961). Transactions of the Association of American Physicians, 74, 353.

Horning, E. S., and Whittick, J. W. (1954). British fournal of Cancer, 8, 451. Leeper, R. D., Benula, R. S., Brener, J. L., and Rawson, R. W. (1960). fournal of Clinical Endocrinology and Metabolism, 20, 1457

Liddle, L., Seegmiller, J. E., and Laster, L. (1959). Fournal of Laboratory and Clinical Medicine, 54, 903.

Llaurado, J. G., Claus, J. L., and Trunnell, J. B. (1962). Endocrinology, $71,598$.
Mikkelsen, W. H. Dodge, H. J, and Valkenberg, H. (1965). American fournal of Medicine, 39, 242 .

Mintz, D. H., Canary, J. J., Carreon, G., and Kyle, L. H. (1961). New England fournal of Medicine, 265, 112 .

Preedy, J. R. K., and Aitken, E. H. (1956). fournal of Clinical Investigation, $35,423$.

Scott, J. T., Dixon, A. St.J., and Bywaters, E. G. L. (1964). British Medical fournal, 1, 1070 .

Scott, J. T., and Pollard, A. C. (1970). Annals of the Rheumatic Diseases, 29,

Thorn, G. W., and Engel, L. L. (1938). Journal of Experimental Medicine, 68, 299.

Trevan, D. (1956). Lancet, 2, 22.

Wolfson, W. Q. et al. (1949). fournal of Clinical Endocrinology and Metabolism, 9, 749 .

\title{
Removal of Polyps with Fibreoptic Colonoscope: A New Approach to Colonic Polypectomy
}

\author{
CHRISTOPHER WILLIAMS, T. MUTO, K. R. P. RUTTER
}

\section{British Medical fournal, 1973, 1, 451-452}

\section{Summary}

By using a colonoscope diathermy snare a total of 75 polyps have been removed from sites throughout the colon in 43 patients. There was some haemorrhage in four cases but no other morbidity, and all patients were discharged home within 24 hours. The ease of this procedure suggests that it should replace colotomy and surgical polypectomy in the management of polyps inaccessible to the rigid sigmoidoscope.

\section{Introduction}

Only about $25^{\circ} \%$ of large-bowel polyps occur within reach of the rigid sigmoidoscope (Arminski and $M=L e a n, 1964$ ) and removal of the remainder has until now been through colotomies during abdominal o peration.

Since the introduction of the fibresigmoidoscope in 1968 and the long colonoscope in 1970 there have been several reports of the use of these instruments in the diagnosis of large-bowel disorders (Salmon et al., 1971; Wolff and Shinya, 1971; Classen, 1971). In the past year Deyhle et al., (1972) and Wolff et al. (1972) have pioneered the technique of colonoscopic polypectomy, reporting the removal of a total of 73 polyps in the distal colon. We now report our clinical experience at St. Mark's hospital in the endoscopic removal of polyps from all parts of the colon, and suggest that this is now the method of choice.

\section{Patients and Method}

All patients had had a previous double contrast barium enema. Most were referred for colonoscopy because of the radiological finding of one or more polyps out of range of the rigid sigmoidoscope. In others a polyp was found during colonoscopy for unexplained rectal bleeding or other symptoms. The diagnosis of familial polyposis coli was taken as an indication for surgery without colonoscopy.

Preparation.-Patients with polyps in the sigmoid or distal descending colon were given a single oxyphenisatin (Veripaque)

St. Mark's Hospital, London EC1V 2PS

CHRISTOPHER WILLIAMS, B.M., M.R.C.P., Research Fellow

T. MUTO, M.D., Honorary Registrar

K. R. P. RUTTER, M.B., F.R.C.s., Research Assistant enema one hour before examination, while those with proximal polyps took a low residue diet and castor oil in addition. A few patients were admitted as day cases and discharged the same evening but most were observed overnight after polypectomy. All patients signed operation consent froms, and serum was obtained for blood grouping from those with larger polyps. No premedication was given but intravenous diazepam was administered before insertion of the colonoscope.

Technique.-With the technique of colonoscopy previously described (Williams and Muto, 1972) polyps could be reached at any point in the colon, and in most cases the whole large bowel was examined to exclude the presence of polyps not seen on barium enema examination. On reaching a polyp a Deyhle (Storz) or A.C.M.I. endoscopic polypectomy snare was passed down the suction/biopsy channel of the instrument and the wire loop was closed near the base of the polyp. Sessile polyps could be raised on a "pedicle" by lifting the snared polyp into the lumen of the bowel. Carbon dioxide was insufflated to obviate any danger of explosion. A slowly increasing current was then applied from a standard diathermy apparatus until local coagulation was visible, followed by a cutting current to sever the polyp. Large single polyps were either sucked onto the tip of the instrument for removal or trapped in a modified Dormia basket. Multiple snared polyps (previously biopsied) were removed with a large-volume oxyphenisatin saline enema immediately after the procedure.

\section{Results}

A total of 75 colonic polyps have been removed from 43 patients. Twenty-nine patients had single polyps $(8 \mathrm{~mm}-3.5 \mathrm{~cm})$, the other 14 patients had up to seven polyps removed $(5 \mathrm{~mm}$ $3.5 \mathrm{~cm}$ ) (figs, 1 and 2). In one patient it proved impossible to snare a polyp on an acute sigmoid flexure. Although most single polyps were in the sigmoid colon (fig. 3), polyps could be snared and recovered from all sites in the colon. Four patients in this series had significant haemorrhage $(100-500 \mathrm{ml}$ approximate blood loss) due to inadequate coagulation before cutting. In each case the haemorrhage stopped spontaneously, although two patients were transfused as a precautionary measure. There were no other complications and no morbidity; all patients left hospital within 24 hours of the procedure. Subsequent histological examination showed that all the polyps removed were adenomas with the exception of three metaplastic polyps (Morson, 1962), seven of Peutz Jeghers type, one juvenile polyp, and one submucous lipoma. No polyp in this series showed evidence of malignancy. 